\title{
Response of rheumatoid arthritis to chemotherapy for Hodgkin's disease in a patient with IgA deficiency and overlap connective tissue disease
}

\author{
MICHAEL G COHEN, ' BEATRICE JANSSEN,' AND JOHN WEBB \\ From the 'Sydney University Rheumatology Department, The Royal North Shore Hospital of Sydney, St \\ Leonards, NSW 2065; and 2129 Nerang St, Southport, Qld 4215. Australia
}

SUMmARY A patient with IgA deficiency presented with classical rheumatoid arthritis (RA) and subsequently, features of multiple other connective tissue diseases (CTD). When Hodgkin's disease later developed the patient received combination chemotherapy, which induced remission of both neoplastic and connective tissue diseases. As the RA remained in remission for three years this case may offer insight into a mode of use of cytotoxic agents in CTD.

Key words: SLE, dermatomyositis, cytotoxic chemotherapy.

Cytotoxic immunosuppressive drug treatment has been given to patients with rheumatoid arthritis (RA) and other connective tissue diseases (CTD) who have proved refractory to conventional second line agents, such as gold salts, D-penicillamine, and antimalarial drugs. They are used either continuously or in pulses, but intermittent use of both cytotoxic drugs and corticosteroids, as for lymphoma, has not been reported in rheumatic diseases uncomplicated by vasculitis.

We present a patient with IgA deficiency and classical RA with subsequent overlap features of Sjögren's syndrome (SS), dermatomyositis (DM), and systemic lupus erythematosus (SLE) who developed Hodgkin's disease. This was managed with combination chemotherapy, and after five years there was no evidence of recurrent lymphoma. Similarly, her RA and overlap CTD remitted, but the RA relapsed after three years and has remained active.

\section{Case report}

A 44 year old white woman when first seen in 1975

Accepted for publication 24 December 1987.

Correspondence to Dr Michacl G Cohen. Sydney University Rheumatology Department. The Royal North Shore Hospital of Sydncy, St Leonards, NSW 2065, Australia. presented with a four month history of symmetrical polyarthritis involving proximal interphalangeal (PIP) and metacarpophalangeal (MCP) joints, wrists, shoulders, knees, ankles, forefeet, and cervical spine, with marked early morning stiffness. There were no clinical features of other CTD at this time. Table 1 shows the haematological and immunological findings, at presentation and subsequently, as the different syndromes evolved. Other investigations: antibodies SS-A, SS-B, Sm, RNP, and Jo-1 were not detected, at this time or subsequently, by counterimmunoelectrophoresis or immunodiffusion; IgA was absent but IgG and IgM were present at normal concentrations; electromyography was normal; and hand radiographs showed periarticular osteoporosis. She was diagnosed as having classical RA and IgA deficiency. Treatment was started with aspirin, indomethacin, and gold.

Over the next two and a half years she developed nodular deforming disease and radiographs showed erosions of several MCP and PIP joints, wrists, and metatarsophalangeal joints. Additionally, she developed marked dryness of her eyes, mouth, and skin and was considered to have RA with SS.

She then presented with painful proximal muscle weakness, Gottron's sign, heliotrope eyelid rash, and a history of pleurisy. An electromyogram and muscle biopsy were consistent with polymyositis, 
Table 1 Sequential laboratory investigations in an IgA deficient woman who progressively developed multiple connective tissue diseases and Hodgkin's disease

\begin{tabular}{|c|c|c|c|c|c|}
\hline & \multicolumn{5}{|l|}{ Date of test } \\
\hline & August' '75 & August' 76 & March'78 & December ' 81 & May 86 \\
\hline Age (years) & 44 & 45 & 47 & 51 & 55 \\
\hline Diagnosis* & RA & RA/SS & $\mathrm{DM} / \mathrm{SLE}$ & HD & RA \\
\hline Haemoglobin $(g / l)$ & 143 & 138 & 132 & 100 & 127 \\
\hline Leucocytes (lymphocytes) $\times 10^{-9} / 1$ & $9 \cdot 0(2 \cdot 3)$ & $8.7(1.9)$ & $4 \cdot 8(0 \cdot 8)$ & $6 \cdot 3(0 \cdot 5)$ & $7 \cdot 6(0.9)$ \\
\hline Platelets $\times 10^{--9} / 1$ & 295 & 220 & 40 & 200 & 223 \\
\hline ESR (mm/1 h, Westergren) & 15 & 31 & 51 & 126 & 28 \\
\hline Rheumatoid factor (RF) $\dagger$ (reciprocal titre) & 64 & 512 & () & 0 & $>256 \ddagger$ \\
\hline Antinuclear antibody $\S$ (reciprocal titre) & 0 & 100 & $2000, S \|$ & $160, \mathrm{H} \|$ & $40, \mathrm{H}$ \\
\hline C3 (g/l) (normal $0 \cdot 5-1 \cdot 15)$ & ND & 0.95 & $0 \cdot 67$ & 1.97 & $0 \cdot 91$ \\
\hline $\mathrm{C} 4(\mathrm{~g} / \mathrm{l})($ normal $0 \cdot 2-0.5)$ & ND & $0 \cdot 29$ & $(0 \cdot 16$ & $0 \cdot 40$ & $0 \cdot 27$ \\
\hline Anti-DNA\% (Farr assay, normal <20) & 3 & 12 & 30 & 28 & 0 \\
\hline Lupus band $\Upsilon$ (immunoglobulin class) & Nil & ND & $\mathrm{G}, \mathrm{M}$ & ND & Nil \\
\hline
\end{tabular}

${ }^{*}$ RA = rheumatoid arthritis; SS=Sjögren's syndrome; DM=dermatomyositis; SLE=systemic lupus erythematosus; HD=Hodgkin' disease.

†RF by sensitised sheep red blood cell agglutination ('Rheumaton').

$\ddagger$ RF by nephelometry (Beckman's) $=2440 \mathrm{U} / \mathrm{l}$.

$\S$ Antinuclear antibody-rat liver substrate.

$\| \mathrm{S}=$ speckled; $\mathrm{H}=$ homogeneous

ПLupus band-immunoglobulin deposition at the dermoepidermal junction detected by direct immunofluorescence.

though the creatine phosphokinase was normal. Corticosteroid treatment was initially declined, but soon after she presented with thrombocytopenia. In addition to previous clinical findings, she now had periungual erythema. Investigations were as follows: as listed in Table 1; bone marrow was hypercellular with normal to increased megakaryocytes on aspirate and trephine; urine analysis showed red blood cells, but intravenous and retrograde pyelography showed medullary sponge kidney and a renal calculus. Prednisolone $50 \mathrm{mg}$ a day was started and within two weeks the platelet count rose to $72 \times 10^{9} / 1$ and more slowly to $120 \times 10^{9} / \mathrm{l}$. The myositis resolved while the RA remained moderately active but with no further progression of the erosions.

In December 1981 she presented with weight loss, episodic fevers, night sweats, and retroperitoneal lymphadenopathy. After full staging she was diagnosed as mixed cellularity Hodgkin's disease, stage IIB. Treatment was started with nitrogen mustard $6 \mathrm{mg} / \mathrm{m}^{2}$, days 1 and 8 ; vincrisine 1.4 $\mathrm{mg} / \mathrm{m}^{2}$, days 1 and 8 ; procarbazine $100 \mathrm{mg} / \mathrm{m}^{2}$, days 1 to 7 ; prednisolone $40 \mathrm{mg} / \mathrm{m}^{2}$, days 1 to 14 (body surface area $1.63 \mathrm{~m}^{2}$ ). Owing to myelosuppression, cyclophosphamide $1 \mathrm{~g}$, day 1 , was substituted for nitrogen mustard after the first course. She received four-weekly cycles for six months after which she was in remission, and has remained so when most recently reviewed almost five years later.

The RA also went into complete remission, but three years later she represented with a flare of polyarthritis. Investigations were again consisten with RA (Table 1). She has to date refused specific antirheumatic treatment and has had progressive severe rheumatoid arthritis.

\section{Discussion}

This woman with IgA deficiency would appear tôे have progressed from classic RA, to RA with $\mathrm{SS}$ and then to DM and SLE, at which time she wasa rheumatoid factor negative. She then developecं Hodgkin's disease, which would seem to have been cured, but after three years in remission RAO recurred without evidence of other CTD.

IgA deficiency is well described in associations with RA and $\mathrm{CTD}^{\prime}$ and may represent a back- $\rightarrow$ ground immunological predisposition to our patienE. developing RA with multiple overlap CTD syn dromes. Similarly, Hodgkin's disease and non* Hodgkin's lymphomas have been described with both IgA deficiency ${ }^{1}$ as well as $\mathrm{RA}^{2}$ and other. CTD. ${ }^{3}$ The presence of both malignancy and auto immune disease in a patient with IgA deficiency io rare, however. Concurrent RA may occur in about $3 \cdot 6-7 \cdot 2 \%$ of patients with SLE. ${ }^{+}$DM or polymyosi $\stackrel{?}{?}$ tis is associated with other CTD in $14-41 \%$ of cases, ${ }^{5}$ while overlap between SS and other CTD is common. It is possible that the DM was paraneo plastic but the duration between it and the onset of Hodgkin's disease would argue against this. Alternatively, Hodgkin's disease may have been a $\operatorname{com}^{-} \mathrm{C}$ plication of one of the CTD, most probably SS. ${ }^{3}$ bue 
this is conjectural. Whereas the recurrence of RA is most likely to have been a relapse of the original disease, it is possibly a second onset of RA in a person with a demonstrated propensity to autoimmune diseases.

Cytotoxic drugs have had extensive use in RA and other CTD for both their direct therapeutic and steroid sparing effects. ${ }^{6}$ They are most commonly used singly, with or without concomitant corticosteroids, and usually administered daily. More recently, pulse therapy with cyclophosphamide has been used in both $\mathrm{RA}^{7}$ and SLE. ${ }^{8}$ Scott and Bacon reported a more favourable outcome with pulse cyclophosphamide and methylprednisolone than with conventional cytotoxic drug treatment in patients with systemic rheumatoid vasculitis. ${ }^{7}$ Significant mortality occurred in both groups, but this seems more related to the considerable mortality of RA complicated by vasculitis ${ }^{7}$ than to drug toxicity. We could find only one open trial in which a multiple drug regimen was used in RA. Csuka et al report that although 16 of 31 patients with intractable RA achieved complete remission with a combination of cyclophosphamide (continuous), azathioprine, and chloroquine, all relapsed when treatment was stopped. ${ }^{9}$ Moreover considerable toxicity was encountered.

In lymphoma, multiple drugs are given in an intermittent protocol in order to cause a degree of myelosuppression with a drug free period to allow bone marrow recovery. Although cytotoxic drug treatment sufficient to cure lymphoma appears likely to be associated with unacceptable toxicity if used for CTD, we could find no reports of the outcome in patients such as ours. Importantly, pulse or intermittent cytotoxic drug administration appears to be associated with less toxicity than continuous oral treatment. ${ }^{78}$ Nonetheless, care is needed to tailor doses to the degree of myelosuppression, ${ }^{8}$ and in our patient cyclophos- phamide was substituted for nitrogen mustard, which had caused unacceptable leucopenia and thrombocytopenia.

Our case demonstrates that antilymphomatous chemotherapy may induce prolonged complete remissions of RA and CTD in patients such as ours. It is unknown whether some patients would gain a permanent remission, that is, be cured. We believe that this case supports a potential place for the intermittent use of both cytotoxic drugs and corticosteroids in the management of patients with refractory RA.

MGC is in receipt of the Frank G Spurway scholarship of The Arthritis Fouridation of Australia: BJ is supported by the Sutton Rheumatism Research Fund. Roval North Shore Hospital: and we thank Miss D Carey for secretarial assistance.

\section{References}

1 Wintrobe M M. Lee G R. Bogs D R. et al. Clinical hematology. Philadelphia: Lea and Febiger. 1981: 138+413.

2 Symmons D P M. Neoplasms of the immune system in rheumatoid arthritis. Am J Med 1985: 78 (suppl 1A): 22-8.

3 Whaley K. Alspaugh M A. Sjögren's syndrome. In: Kelley W N. Harris E D. Ruddy S. Sledge C B. eds. Textbook of rheumatology. Philadelphia: Saunders. 1985: 956-78.

4 Cohen M G. Webb J. Concurrence of rheumatoid arthritis and systemic lupus erythematosus: report of 11 cases. Ann Rheum Dis 1987; 46: 853-8.

5 Tymms K E. Webb J. Dermatopolymyositis and other connective tissue diseases: a review of 105 cases. J Rheumatol 1985: 12: $1140-8$.

6 Steinherg A D. Plotz P H. Wolff S M. Wong V G. Agus S G. Decker $J$ L. Cytoxic drugs in treatment of nonmalignant discases (NIH conference). Ann Intern Med 1972: 76: 619-42.

7 Scott D G I. Bacon P A. Intravenous cyclophosphamide plus methylprednisolone in treatment of systemic rheumatoid vasculitis. Am J Med 1984: 76: 377-83.

8 Austin H A, Klippel J H, Balow J E, et al. Therapy of lupus nephritis: controlled trial of prednisone and cytotoxic drugs. $N$ Engl J Med 1986; 314: 614-9.

9 Csuka M E, Carrera G F, McCarty D J. Treatment of intractable rheumatoid arthritis with combined cyclophosphamide, azathioprine, and hydroxychloroquine. A follow-up study. JAMA 1986; 255: 2315-9. 